\title{
Radial Distortion of the Arthroscopic Transtibial Portal: A 2-Dimensional in Vitro Model
}

\author{
Miodrag Vranješ' ${ }^{1,2}$, Željka Cvejić ${ }^{3}$, Nataša Todorović ${ }^{3}$, Zoran Gojković1,2, Vladimir Harhaji1,2 \\ ${ }^{1}$ Faculty of Medicine, University of Novi Sad, Novi Sad, Serbia \\ ${ }^{2}$ Department of Orthopedic Surgery and Traumatology, Clinical Center of Vojvodina, Novi Sad, Serbia \\ ${ }^{3}$ Faculty of Natural Sciences, Department of Physics, University of Novi Sad, Novi Sad, Serbia \\ Email: *miodrag.vranjes@mf.uns.ac.rs
}

How to cite this paper: Vranješ, M., Cvejić, Z., Todorović, N., Gojković, Z. and Harhaji, V. (2020) Radial Distortion of the Arthroscopic Transtibial Portal: A 2-Dimensional in Vitro Model. Open Access Library Journal, 7: e6035.

https://doi.org/10.4236/oalib.1106035

Received: December 30, 2019

Accepted: January 7, 2020

Published: January 10, 2020

Copyright $\odot 2020$ by author(s) and Open Access Library Inc.

This work is licensed under the Creative Commons Attribution International License (CC BY 4.0).

http://creativecommons.org/licenses/by/4.0/

\section{(c) (i) Open Access}

\begin{abstract}
Purpose: To make the positioning of the anterior cruciate ligament (ACL) transplants as precise as possible, it is necessary to better visualize the footprint. Identifying anatomic sites is complicated by image distortion inherent in arthroscopy. The standard "Outside-In" ACL reconstruction technique involves drilling a tunnel, i.e. an aperture on the surface of the tibia for the purpose of placing the bone-tendon-bone transplant. This operative technique opens another approach to the inside of the knee, through the tibial plateau (Transtibial-TT). The aim of this manuscript is to assess optimal arthroscopic visibility by calculating radial distortion, arthroscopy insertion positions and different knee bending angles. Methods: We used a standard dot array calibration pattern, an arthroscopic imaging system and Sawbones ${ }^{\circledR}$ knee models. The standard deviation and relative standard deviation of distances obtained at distortion of the images were calculated. Results: All captured imagines have shown the effect of distortion so called fish-eye view, i.e. the imagines at periphery were more curved and compressed. Conclusion: The least distorted arthroscopic image of the femoral ACL footprint can be obtained when using the TT portal and by bending the knee between $90^{\circ}$ and $130^{\circ}$ with a $30^{\circ}$ arthroscope. Also, the best visualization is performed by drilling the tibia under the angle $0^{\circ}$ in the sagittal plane and $23^{\circ}$ in the coronal plane in comparison to the tibial surface.
\end{abstract}

\section{Subject Areas}

Biophysics

\section{Keywords}

Transtibial Portal, Anterior Cruciate Ligament (ACL), Radial Distortion, 


\section{Introduction}

In arthroscopic anterior cruciate ligament (ACL) reconstruction, anatomic accuracy of transplant placement is critical for the clinical success [1] [2] [3]. The most used portals in knee arthroscopy are the anterolateral (AL) and anteromedial (AM). The AL is mainly used as the viewing portal, and the AM portal is used as the working portal. Some articles advocate the use of AM portal technique with the knee placed in hyperflexion when performing femoral tunnel drilling [4] [5]. On the contrary, others perform femoral tunnel drilling through the tibia [6]. To make the positioning of ACL transplants as precise as possible, it is necessary to better visualize the footprint i.e. point of anatomic transplant placement. Inadequate visualization of femoral footprint through the lateral portal can cause surgical error, anterior and more vertical femoral tunnel placement or bending with damage to the telescope [7] [8]. Identifying anatomic sites is complicated by image distortion inherent in arthroscopy. Considering this curvature of the image on the monitor, as well as the angle under which the ligament insertion site is observed, it can be concluded that it is difficult to achieve adequate accuracy of observation [9]. The assumption is that if we increase the angle of insertion site observation, or approach $90^{\circ}$ in relation to the plane formed by the inner side of the external condyle of the femur, we will get visibility that is far better and the mistake in the orientation of the transplant is lower. A greater angle of observation would be possible only through the possible third portal [10]. The standard "Outside-In" ACL reconstruction technique involves drilling a tunnel, i.e. an aperture on the surface of the tibia for the purpose of placing the bone-tone-bone transplant. This operative technique opens another way in the knee, it is a portal through the tibial plateau (Transtibial-TT). The hypothesis is that if introducing optics through this portal, in which the arthroscope can get closer to the site of the ACL footprint, the viewing angle on the plane of the condyle surface is greater, and the curvature of the image would be smaller. Also, we try to find the most adequate tibial drilling angle and the most favorable angle of knee bending during surgery.

\section{Materials and Methods}

The arthroscopic imaging system used (Karl Storz, 28731 bwa, Germany 2014) was standard, providing a circular arthroscopic image within $1920 \times 1080$ pixel display. We used a dot array calibration pattern (Figure 1). Dots arranged in horizontal and vertical grid lines at square area with a separation of $0.92 \mathrm{~mm}$. The distances between each dot and its four nearest neighbors were equals as in the paper published by Hoshino Y. et al. [11].

The calibration pattern is placed at the lateral wall of the medial femoral 


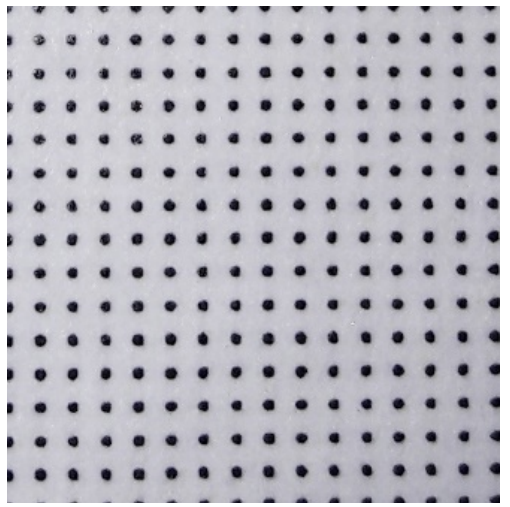

Figure 1. The dot array calibration pattern, dots are separated by $0.92 \mathrm{~mm}$.

condyle in five Sawbones ${ }^{\circledR}$ knee models (Arthrex replaceable bone model of left femur and tibia, SB-1414, Germany 2016) (Figure 2). All five Sawbones ${ }^{\circledR}$ were drilled under different angles (Table 1) with a tibial guide (Karl Storz, Tutlingen, Germany) and were fixed to a custom-made framework with a movable knee flexion angle (Figure 2). Drilling was performed with a $10 \mathrm{~mm}$ drill and the tibial guide was adjusted to $50^{\circ}$. The guide pin was placed at the inner border of the anterior horn of the lateral meniscus in all Sawbone ${ }^{\varpi}$ models. The extra articular starting point was $1 \mathrm{~cm}$ medial to the tuberositas tibiae and $1.5 \mathrm{~cm}$ proximal to the upper rim of the pes anserinus projection, $0.5 \mathrm{~cm}$ medial to the tuberositas and $2 \mathrm{~cm}$ proximal to the pes anserinus, $2 \mathrm{~cm}$ medial to the tuberositas and $2 \mathrm{~cm}$ proximal to the pes anserinus, $1 \mathrm{~cm}$ medial to the tuberositas and $2 \mathrm{~cm}$ proximal to the pes anserinus and finally $1.3 \mathrm{~cm}$ medial to the tuberositas and $1 \mathrm{~cm}$ proximal to the pes anserinus. Using plain radiography of the Sawbones ${ }^{\oplus}$, different angles of the tibial tunnel were calculated (Figure 3). The AM and AL portals were simulated by $9 \mathrm{~mm}$ screw eyes (Remex doo, Croatia). The AM portal was set $1 \mathrm{~cm}$ above the joint line and medial to the line connecting the medial edge of the tibial tuberosity with the medial wall of the intercondylar notch in a bent knee, according to the position described by Zantop et al. [12]. The AL portal was set at $1.5 \mathrm{~cm}$ above the joint line and along the line connecting the lateral edge of the tibial tuberosity with the lateral wall of the intercondylar notch.

The arthroscopic images of the intercondylar lateral wall were taken through the AM, AL or TT portal using five different Sawbones ${ }^{\circledast}$ models and using six different flexion angles. The AM and AL portal were not repeated for every Sawbone ${ }^{\oplus}$ model as was the TT portal. Two examiners (VM and HV) independently took three or more images of the lateral wall for each combination. Care was taken to capture the greatest area of the lateral wall as possible. During the experiment, the position of the arthroscope was about $10 \mathrm{~mm}$ from the grid of dots (Figure 4). The calibration pattern was imaged using $30^{\circ}$ arthroscope through AM, AL and TT portal at seven different angles $\left(30^{\circ}, 50^{\circ}, 70^{\circ}, 90^{\circ}, 110^{\circ}\right.$ and $130^{\circ}$ ) of knee position. We used the $30^{\circ}$ arthroscopy who is the most used nowadays [13]. The distances for seven selected dots in fifth row and fifth column 


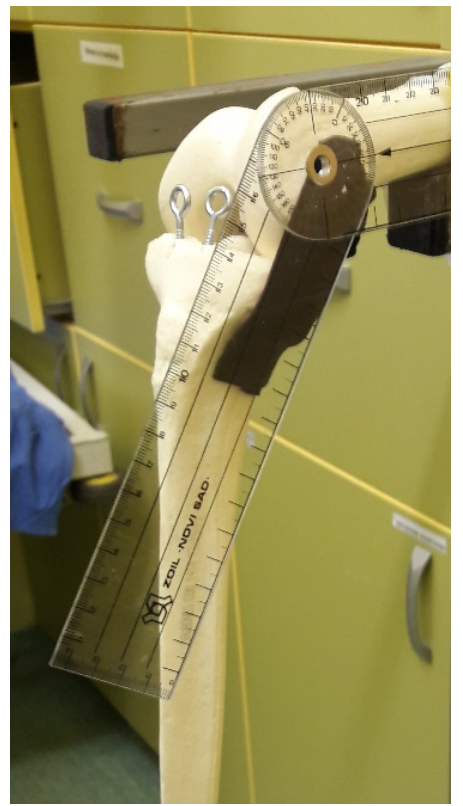

Figure 2. Sawbones ${ }^{\oplus}$ models with different extra articular starting points and measuring the bending angle in one model.
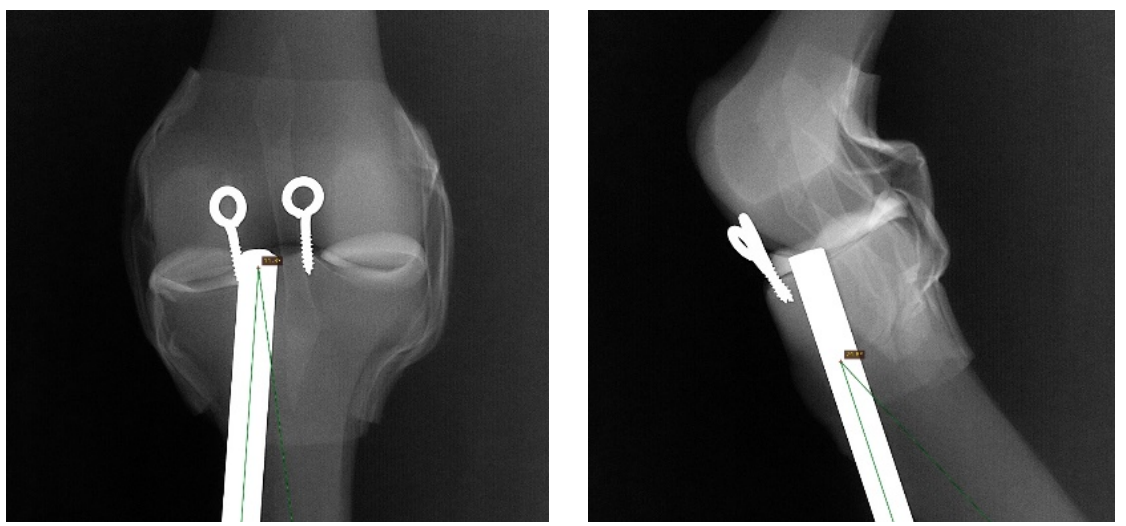

Figure 3. Plain radiography of the Sawbones ${ }^{\circledR}$. Measuring coronal and sagittal tibial drilling angle.
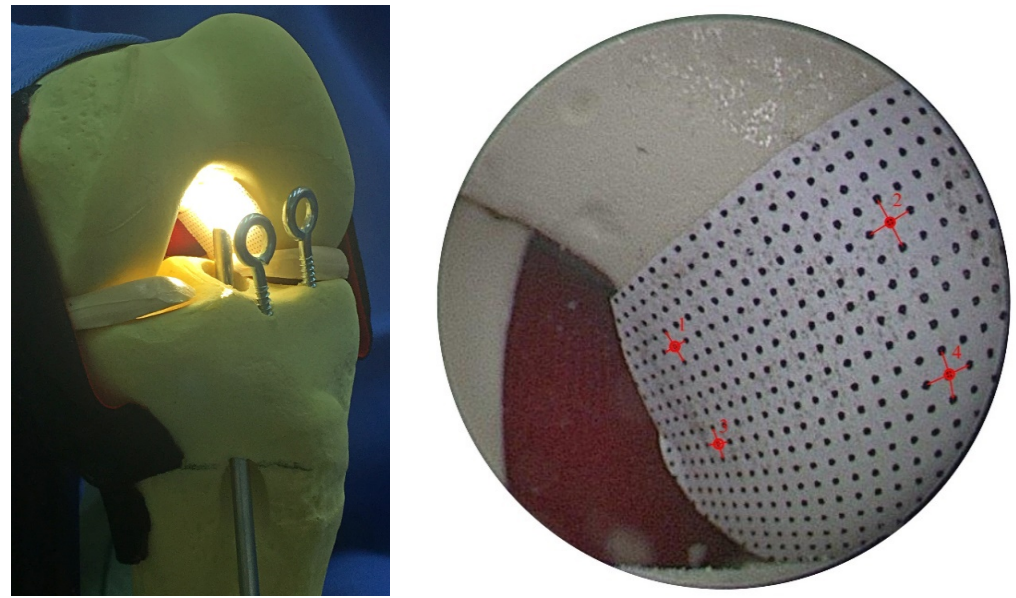

Figure 4. Taking an image through the TT portal. 
Table 1. Different tibial knee models and drilling angles in relation to the diaphyseal axis.

\begin{tabular}{cccccc}
\hline & Knee No. 0 & Knee No. 1 & Knee No. 2 & Knee No. 3 & Knee No. 4 \\
\hline Coronal angle $\left[{ }^{\circ}\right.$ ] & 11 & 0 & 26 & 14 & 16 \\
Sagital angle $\left[{ }^{\circ}\right]$ & 24 & 23 & 27 & 39 & 22 \\
\hline
\end{tabular}

in deep and shallow region of calibration pattern and corresponding dot in vertical and horizontal direction were measured. A typical distorted image of the grid is shown in Figure 5, and it can be noticed that the distances between dots compressed more at the ages of the arthroscopic image and widespread around the distortion center.

\section{Results and Discussions}

The image captured by arthroscopic endoscope show radial distortion. Radial distortion is caused by the shape of the lens and, at the same time, is correlated with the focal length. The distortion introduces nonlinear changes in the image. In the case of the positive radial distortion (barrel distortion) areas near the distortion center compressed more. As a consequence, the outer areas of the distorted image look smaller than the real size. Barrel distortion is common for wide angle designed endoscope lens. There are several methods which have been presented for the nonlinear distortion correction [14]-[19]. The even-order polynomial model is one of the frequently used distortion models which enables good enough distortion correction of the endoscopic image. In other words, the relation of coordinates between the real image $r^{u}$ and distorted image $r^{d}$ could be written as follow:

$$
r^{d}=r^{u}\left(1+k_{1} r^{u 2}+k_{2} r^{u 4}+k_{3} r^{u 6}+\cdots\right)
$$

where $r^{d}$ and $r^{u l}$ can be calculated as follow:

$$
r^{d}=\sqrt{\left(x_{2}^{d}-x_{1}^{d}\right)^{2}+\left(y_{2}^{d}-y_{1}^{d}\right)^{2}} \text { and } r^{u}=\sqrt{\left(x_{2}^{u}-x_{1}^{u}\right)^{2}+\left(y_{2}^{u}-y_{1}^{u}\right)^{2}}
$$

The Descartes coordinates $x^{u}$ and $y^{u}$ represent coordinates on a planar calibration pattern, and $x^{d}$ and $y^{d}$ are coordinates of corresponding point in the distorted image. Furthermore, the relation between distorted and undistorted coordinates may be described by $r_{i}^{d}=\lambda\left(r_{i}^{u}\right)$ where $\lambda$ represents distortion ratio and depends on the chosen point with position $r^{\prime \prime}$. Assuming that the distortion ratio is equal to unity near the center of distortion. Based on the size of the radial distortion of images captured by camera for different insert position (AM, AL and TT) of the arthroscopic instrument and for different knee positions during surgery, the idea of this manuscript is to assess optimal visibility for surgeon during the operation. Before we calculated the distance between two dots for selected columns and rows, we have made two assumptions:

- The center of distortion is close to the image center.

- The distortion is circularly symmetric i.e. amount of distortion is dependent only on dot's distance from the center of distortion. 


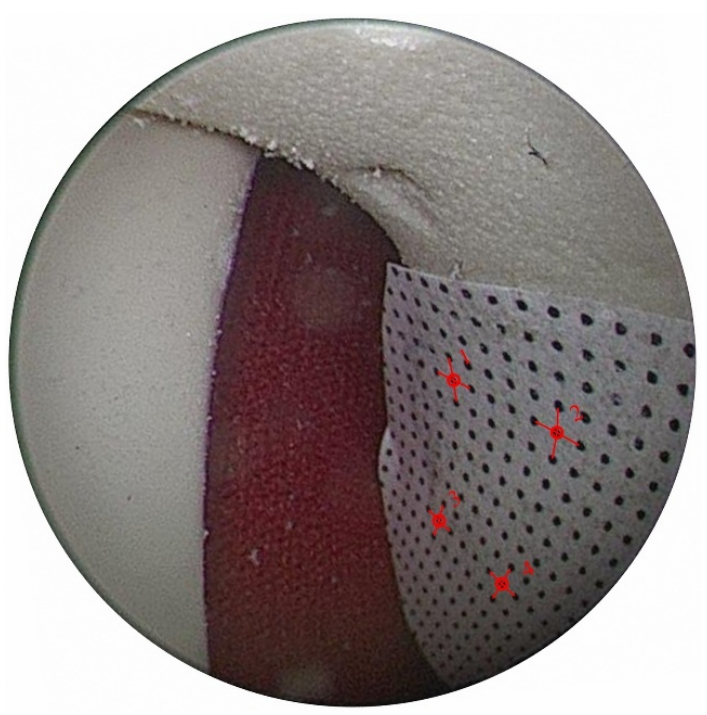

Figure 5. Images of the dot patterns taken from the TT portal.

Radial distortion in deep and shallow region was calculated using Equation (2). Then we calculated standard deviation and relative standard deviation of distances obtained at the distortion images. This is a more convenient way to deal with the situation of the smallest distortion effects. The relatively standard deviations for radial distortion of three different knee models for different knee angle positions are given in order in Table 2 and Table 3.

Analyzing the obtained data given in previous tables, i.e. the relative standard deviation for different portal locations with different knee positions, the first thing one notes is that TT portal technique produced the least distortion in arthroscopic image. The second thing which appears is that image distortion is best minimized by a knee position between $110^{\circ}$ and $130^{\circ}$. As described by Hoshino et al. [10], when the knee is bent, the posterior margin of the lateral femoral condyle can be seen more clearly due to the weaker and shallow position of the arthroscopic view. So, it would appear that surgeons can identify landmarks more easily by flexing the knee $110^{\circ}$ then by lower flexion angels. This recognition coincides with our study, although we use another portal. On the contrary, the same paper recommended to use the $90^{\circ}$ knee flexion angle when determining femoral tunnel placement, but by using the AM portal. According to Hoshino et al. [9] it appears that image distortion is best minimized by a position in which the line-of-sight of the arthroscope is directly perpendicular to the image. In consideration of their findings, surgeons should position the target in the center of the image whenever possible and use a straight viewing angle [9]. Also, the authors outlined that the $0^{\circ}$ lens angle creates the least distortion, but working with such an arthroscopy in nearly impossible and it needs changing additional arthroscopy lenses during the procedure. Hyper flexing the knee to the described $110^{\circ}-130^{\circ}$ is also associated with complications, including loss of visualization, fat pad ingress, poor arthroscopic inflow, inability to sea instrumentation, and bending of rigid guide wires [20] [21]. 
Table 2. Comparison of the relative standard deviation of radial distortion in Knee No 1 through the AM, AL and TT portal using different angles of knee position.

\begin{tabular}{cccc}
$\begin{array}{c}\text { Angle of } \\
\text { knee position } \\
{\left[^{\circ}\right]}\end{array}$ & $\begin{array}{c}\text { AM portal } \\
\text { relatively standard } \\
\text { deviation of } \\
\text { radial distortion [\%] }\end{array}$ & $\begin{array}{c}\text { AL portal } \\
\text { relatively standard } \\
\text { deviation of } \\
\text { radial distortion [\%] }\end{array}$ & $\begin{array}{c}\text { TT portal } \\
\text { relatively standard } \\
\text { deviation of } \\
\text { radial distortion [\%] }\end{array}$ \\
\hline 30 & no visibility & no visibility & 0.95 \\
50 & 0.68 & 1.24 & 0.68 \\
70 & 1.46 & 1.20 & 0.54 \\
90 & 1.10 & 1.27 & 0.15 \\
110 & 0.40 & 1.18 & 0.15 \\
130 & 0.10 & 0.70 & 0.08 \\
\hline
\end{tabular}

AM: anteromedial, AL: anterolateral, TT: transtibial, ${ }^{a}$ visualization in not possible due to impingement of the arthroscope.

Table 3. Comparison of the relative standard deviation of radial distortion in Knee No. 4. through the AM, AL and TT portal using different angles of knee position.

\begin{tabular}{cccc}
\hline $\begin{array}{c}\text { Angle of } \\
\text { knee position } \\
{\left[^{\circ}\right]}\end{array}$ & $\begin{array}{c}\text { AM portal } \\
\text { relatively standard } \\
\text { deviation of } \\
\text { radial distortion [\%] }\end{array}$ & $\begin{array}{c}\text { AL portal } \\
\text { relatively standard } \\
\text { deviation of } \\
\text { radial distortion [\%] }\end{array}$ & $\begin{array}{c}\text { TT portal } \\
\text { relatively standard } \\
\text { deviation of } \\
\text { radial distortion [\%] }\end{array}$ \\
\hline 30 & no visibility & not clear & not clear \\
50 & 1.56 & not clear & not clear \\
70 & 1.00 & not clear & 0.21 \\
90 & 0.62 & 0.57 & 0.36 \\
110 & 0.35 & 0.48 & 0.24 \\
130 & 0.63 & 0.80 & 0.62 \\
\hline
\end{tabular}

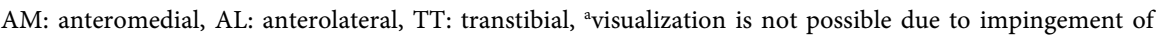

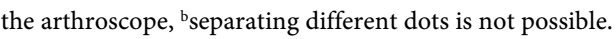

There were some limitations of this study. First, all images are made by two observers. In comparison to other studies that were at least two observers were involved, but independently [22] [23]. In our study two participants calculated the deviation of radial distortion. Second, the Sawbones ${ }^{\varpi}$ knee models have no patellar tendon. Therefore, the position of AM and AL portals is subject to certain positional errors. Lastly, only two standard portal positions were tested and compared to the TT portal. Also, the measurements were not performed in a saline solution as it was by Hoshino et al. [11]. Future studies are needed to measure radial distortion of the image through additional viewing portals, and in combination with immerging the models in saline solution.

\section{Conclusion}

Magnification and shape of the image are inconsistent using different viewing portals and knee bending angles. The least distorted and the most consistent 
arthroscopic image of the femoral footprint can be obtained when using the TT portal and by bending the knee to $90^{\circ}-130^{\circ}$ with a $30^{\circ}$ arthroscope. Also, the best visualization is performed by drilling the tibia using a $50^{\circ}$ guide pin with the extra articular starting point $0.5 \mathrm{~cm}$ medial to the tuberositas tibiae and $2 \mathrm{~cm}$ proximal to the upper rim of the pes anserinus projection. Future studies are needed to evaluate the measured angles in vivo and to calculate the postoperative performance using this method.

\section{Acknowledgements}

Our gratitude to Professor Milankov M. from the Department of Surgery at the University of Novi Sad for assisting in technical details and support.

\section{Funding}

There is no funding source.

\section{Ethical Approval}

This article does not contain any studies with human participants or animals.

\section{Conflicts of Interest}

The authors declare that they have no conflict of interest.

\section{References}

[1] Aglietti, P., Buzzi, R., Giron, F., Simeone, A.J.V. and Zaccherotti, G. (1997) Arthroscopic-Assisted Anterior Cruciate Ligament Reconstruction with the Central Third Patellar Tendon. A 5-8-Year Follow-Up. Knee Surgery, Sports Traumatology, Arthroscopy, 5, 138-144. https://doi.org/10.1007/s001670050041

[2] Khalfayan, E.E., Sharkey, P.F., Alexander, A.H., Bruckner, J.D. and Bynum, E.B. (1996) The Relationship between Tunnel Placement and Clinical Results after Anterior Cruciate Ligament Reconstruction. The American Journal of Sports Medicine, 24, 335-341. https://doi.org/10.1177/036354659602400315

[3] Sommer, C., Friederich, N.F. and Muller, W. (2000) Improperly Placed Anterior Cruciate Ligament Grafts: Correlation between Radiological Parameters and Clinical Results. Knee Surgery, Sports Traumatology, Arthroscopy, 8, 207-213. https://doi.org/10.1007/s001670000125

[4] Bottoni, C.R., Liddell, T.R., Trainor, T.J., Freccero, D.M. and Lindell, K.K. (2008) Postoperative Range of Motion Following Anterior Cruciate Ligament Reconstruction Using Autograft Hamstrings: A Prospective, Randomized Clinical Trial of Early versus Delayed Reconstructions. The American Journal of Sports Medicine, 36, 656-662. https://doi.org/10.1177/0363546507312164

[5] Harner, C.D., Honkamp, N.J. and Ranawat, A.S. (2008) Anteromedial Portal Technique for Creating the Anterior Cruciate Ligament Femoral Tunnel. Arthroscopy, 24, 113-115. https://doi.org/10.1016/j.arthro.2007.07.019

[6] Jaecker, V., Zapf, T., Naendrup, J.H., Pfeiffer, T., Kanakamedala, A.C., et al. (2017) High Non-Anatomic Tunnel Position Rates in ACL Reconstruction Failure Using Both Transtibial and Anteromedial Tunnel Drilling Techniques. Archives of Orthopaedic and Trauma Surgery, 137, 1293-1299. 
https://doi.org/10.1007/s00402-017-2738-3

[7] Vaseenon, T., Phisitkul, P., Wolf, B.R., Femino, J.E. and Amendola, A. (2011) Preventing Damage to Arthroscopic Lens during Surgery. Arthroscopy, 27, 404-408. https://doi.org/10.1016/j.arthro.2010.07.019

[8] Carlsen, A. (1986) A Broken Telescope: A Complication of Arthroscopy. Arthroscopy, 2, 182-183. https://doi.org/10.1016/S0749-8063(86)80064-0

[9] Hoshino, Y., Rothrauff, B., Hensler, D., Fu, F. and Musahl, V. (2016) Arthroscopic Image Distortion Part I: The Effect of Lens and Viewing Angles in a 2-Dimensional in Vitro Model. Knee Surgery, Sports Traumatology, Arthroscopy, 24, 2065-2071. https://doi.org/10.1007/s00167-014-3336-3

[10] Hoshino, Y., Nagamune, K., Yagi, M., Araki, D., Nishimoto, K., et al. (2009) The Effect of Intraoperative Knee Flexion Angle on Determination of Graft Location in the Anatomic Double-Bundle Anterior Cruciate Ligament Reconstruction. Knee Surgery, Sports Traumatology, Arthroscopy, 17, 1052-1060. https://doi.org/10.1007/s00167-009-0773-5

[11] Hoshino, Y., Rothrauff, B.B., Hensler, D., Fu, F.H. and Musahl, V. (2016) Arthroscopic Image Distortion Part II: The Effect of Lens Angle and Portal Location in a 3D Knee Model. Knee Surgery, Sports Traumatology, Arthroscopy, 24, 2072-2078. https://doi.org/10.1007/s00167-014-3268-y

[12] Zantop, T., Haase, A.K., Fu, F.H. and Petersen, W. (2008) Potential Risk of Cartilage Damage in Double Bundle ACL Reconstruction: Impact of Knee Flexion Angle and Portal Location on the Femoral PL Bundle Tunnel. Archives of Orthopaedic and Trauma Surgery, 128, 509-513. https://doi.org/10.1007/s00402-007-0480-y

[13] McMillan, S., Saini, S., Alyea, E. and Ford, E. (2017) Office-Based Needle Arthroscopy: A Standardized Diagnostic Approach to the Knee. Arthroscopy Techniques, 6, 1119-1124. https://doi.org/10.1016/i.eats.2017.03.031

[14] Lubowitz, J.H. (2009) Anteromedial Portal Technique for the Anterior Cruciate Ligament Femoral Socket: Pitfalls and Solutions. Arthroscopy, 25, 95-101. https://doi.org/10.1016/j.arthro.2008.10.012

[15] Bedi, A. and Altchek, D.W. (2009) The "Footprint" Anterior Cruciate Ligament Technique: An Anatomic Approach to Anterior Cruciate Ligament Reconstruction. Arthroscopy, 25, 1128-1138. https://doi.org/10.1016/j.arthro.2009.03.008

[16] Cho, Y., Cho, J. and Kim, D. (2012) Normal Sagittal of the Anterior Cruciate Ligament Can Be Reproduced Using Accessory Anteromedial Portal Technique: A Magnetic Resonance Imaging Study. Archives of Orthopaedic and Trauma Surgery, 132, 1011-1019. https://doi.org/10.1007/s00402-012-1498-3

[17] Guler, O., Mahırogulları, M., Mutlu, S., Cerc1, M.H., Seker, A., et al. (2016) Graft Position in Arthroscopic Anterior Cruciate Ligament Reconstruction: Anteromedial versus Transtibial Technique. Archives of Orthopaedic and Trauma Surgery, 136, 1571-1580. https://doi.org/10.1007/s00402-016-2532-7

[18] Brown, D.C. (1971) Close-Range Camera Calibration. Photogrammetric Engineering, 37, 855-866.

[19] Brown, D.C. (1966) Decentering Distortion of Lenses. Photogrammetric Engineering, 32, 444-462.

[20] Drap, P. and Lefèvre, J. (2016) An Exact Formula for Calculating Inverse Radial Lens Distortions. Sensors, 16, 807. https://doi.org/10.3390/s16060807

[21] Dougherty, G. (2009) Digital Image Processing for Medical Applications. Cambridge University Press, New York. https://doi.org/10.1017/CBO9780511609657 
[22] Hartley, R. and Kang, S.B. (2007) Parameter-Free Radial Distortion Correction with the Center of Distortion Estimation. IEEE Transactions on Pattern Analysis and Machine Intelligence, 29, 1309-1321. https://doi.org/10.1109/TPAMI.2007.1147

[23] Asari, K.V., Kumar, S. and Radhakrishnan, D. (1999) A New Approach for Nonlinear Distortion Correction in Endoscopic Images Based on Least Squares Estimation. IEEE Transactions on Medical Imaging, 18, 345-354.

https://doi.org/10.1109/42.768843 